University of Massachusetts Amherst

ScholarWorks@UMass Amherst

\title{
100th Anniversary of Macromolecular Science Viewpoint: Opportunities in the Physics of Sequence-Defined Polymers
}

\author{
Sarah L. Perry \\ University of Massachusetts Amherst \\ Charles E. Sing \\ University of Illinois at Urbana-Champaign
}

Follow this and additional works at: https://scholarworks.umass.edu/che_faculty_pubs

Part of the Chemical Engineering Commons

\section{Recommended Citation}

Perry, Sarah L. and Sing, Charles E., "100th Anniversary of Macromolecular Science Viewpoint: Opportunities in the Physics of Sequence-Defined Polymers" (2020). ACS Macro Letters. 885.

http://dx.doi.org/10.1021/acsmacrolett.0c00002

This Article is brought to you for free and open access by the Chemical Engineering at ScholarWorks@UMass Amherst. It has been accepted for inclusion in Chemical Engineering Faculty Publication Series by an authorized administrator of ScholarWorks@UMass Amherst. For more information, please contact scholarworks@library.umass.edu. 


\title{
$100^{\text {th }}$ Anniversary of Macromolecular Science Viewpoint: Opportu- nities in the Physics of Sequence-Defined Polymers
}

\author{
Sarah L. Perry ${ }^{\dagger}$ and Charles E. Sing* \\ 'Department of Chemical Engineering, University of Massachusetts Amherst, 686 North Pleasant St. Amherst, MA 01003. \\ *Department of Chemical and Biomolecular Engineering, University of Illinois at Urbana-Champaign, 600 S. Mathews Ave. \\ Urbana, IL 61801.
}

\begin{abstract}
Polymer science has been driven by ever-increasing molecular complexity, as polymer synthesis expands an alreadyvast palette of chemical and architectural parameter space. Copolymers represent a key example, where simple homopolymers have given rise to random, alternating, gradient, and block copolymers. Polymer physics has provided the insight needed to explore this monomer sequence parameter space. The future of polymer science, however, must contend with further increases in monomer precision, as this class of macromolecules moves ever closer to the sequence-monodisperse polymers that are the workhorses of biology. The advent of sequence-defined polymers gives rise to opportunities for material design, with increasing levels of chemical information being incorporated into long-chain molecules; however, this also raises questions that polymer physics must address. What properties uniquely emerge from sequence-definition? Is this circumstance dependent? How do we define and think about sequence dispersity? How do we think about a hierarchy of sequence effects? Are more sophisticated characterization methods, as well as theoretical and computational tools needed to understand this class of macromolecules? The answers to these questions touch on many difficult scientific challenges, setting the stage for a rich future for sequence-defined polymers in polymer physics.
\end{abstract}

Polymers are sequence-defined when the precise pattern of monomers is the same for all of a set or subset of molecules, ${ }^{1,2}$ going beyond sequence-controlled polymers with merely statistical monomer patterns. ${ }^{3}$ Truly sequence-defined polymers remain an elusive goal for polymer chemists; sequencedefinition implies a level of synthetic control ${ }^{4}$ only achievable in a few cases outside the realm of biology, and even then with limitations on chain length or the amount of material. ${ }^{4-7}$ However, motivated by the ubiquity and importance of sequencedefined macromolecules in biological systems, the goal of sequence-definition is being increasingly realized ${ }^{4-13}$ and the boundaries of polymer chemistry are being pushed ever further from the simple copolymers that have dominated polymer science for the past 100 years. We still have alternating, random, blocky, and gradient copolymers $;{ }^{14,15}$ however, it is realistic now to imagine synthetic polymers that must be described by the specific sequence of monomer units rather than a few statistical parameters (i.e., monomer fraction, reactivity ratios, block length, etc.).

The focus of this viewpoint is to highlight the immense challenges in translating synthetic advances in sequence control into new materials, though we refer the reader elsewhere for details on the synthetic techniques. ${ }^{4-6,-13}$ Realized applications of sequence-defined polymers have focused on e.g., information storage, ${ }^{16}$ relying on the ordering of monomers as covalently dictated by the chemist, or as tunable biomaterials ${ }^{17}$ specifically designed to penetrate cells,${ }^{18}$ interact with receptors, ${ }^{19}$ or undergo programmed degradation. ${ }^{20}$ These ideas stem from innumerable examples of sequence-defined biomacromolecules that assemble into complicated and hierarchical structures. ${ }^{6}$ It is these secondary and higher-order structures and their behavior in the presence of other, similarly compli- cated biomacromolecules - that are driven by physical phenomena that lead to biological function. These examples from the biological world hint at the potential for using polymer sequence as a tool for the molecular engineering of soft materials. However, the disparity in the types of synthetic materials that can be designed today, as compared to the elegance of biology highlights the urgent need for polymer physics to begin to bridge the gap between chemical information and soft material properties.

Polymer physics has a role to play in addressing this grand challenge - this community has the tools to ask and address many questions about sequence-defined polymers. How do we understand, measure, and develop theories to predict their properties? Also, what do we ultimately want to do with sequence-defined polymers?

\section{Sequence-Defined Polymers - Beyond Biomacromolecules}

In asking these questions, it is important to clarify distinctions and similarities between fields in close proximity. Biophysics especially shares an interest in sequence-defined polymers via information storage and folded structures in DNA, ${ }^{21,22}$ RNA $^{23,24}$ and proteins. ${ }^{25-27}$ Protein folding, in particular, has shared an historic lineage with polymer physics, but has tended to focus on different types of systems. ${ }^{25} \mathrm{We}$ suggest an arbitrary but useful distinction - protein folding is primarily concerned with specific biological systems and a small number of well-defined, folded, low-energy states. ${ }^{25-28}$ In contrast, work in sequence-defined polymers is (i) interested in an expanded palette of non-biological monomers, (ii) consists of polymer chains that sample a broad continuum of molecular conformations, and (iii) seeks to establish design rules for building materials instead of affecting biophysical processes. This distinction is intended to be fluid and not mu- 
tually exclusive (e.g., in the case of intrinsically disordered proteins, IDPs) ${ }^{29,30}$ however, it remains a useful reminder that viewing sequence-defined polymers through a polymer physics lens provides new perspectives, even as we look to this neighboring discipline for tools and inspiration.

\section{Sequence vs. Spatial Length Scales}
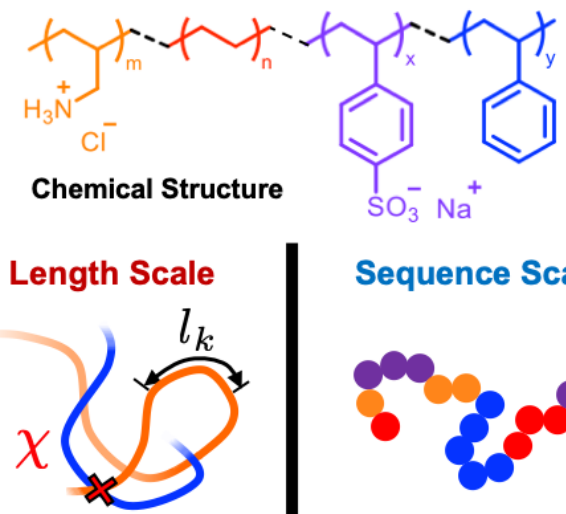

Local interactions, chain statistics (1-10 nm)

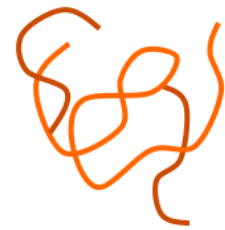

Chain conformation, architecture (10-50 $\mathrm{nm})$

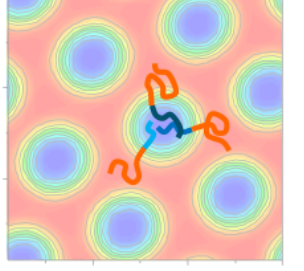

Multi-chain selfassembly (50-200 $\mathrm{nm})$

\section{Sequence Scale}
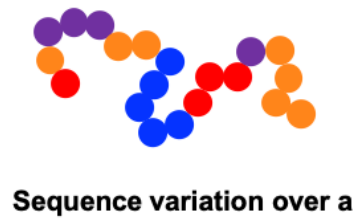

few monomers $(\zeta \approx 1-5)$

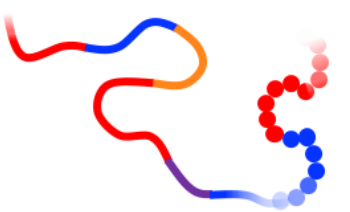

(Short-block) multiblock copolymers $(\zeta \approx 5-20)$

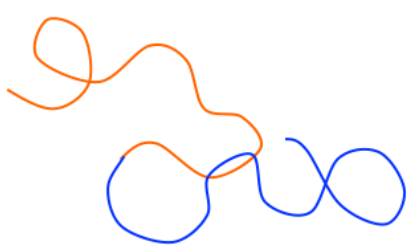

Block copolymers $(\zeta \approx N)$

Figure 1: Length vs. Sequence Scales. In traditional polymer physics, chemical structure gives rise to a hierarchy of increasingly large length scale effects; first, the persistence length $l_{k}$ and local interactions $\chi$ that parameterize chemical structure, affect the overall chain conformation and architecture. Self-assembled structure can therefore arise from multiple, interacting chains. With sequence precision, we suggest a concomitant hierarchy of sequence scales related to the number of monomers involved in the variation of monomer identity. This ranges from variation only over a few monomers (small $\zeta$ ) to full block copolymers (large $\zeta$ ).

The central paradigm of soft matter physics is the importance of length scales and energy scales in determining physical properties. ${ }^{15,31}$ Equilibrium structure in soft materials arises from the coupling between these two characteristics, often leading to the formation of a hierarchy of length scales due to the competition between important molecular interactions. For example, the self-assembled structure of melt block copolymers $^{32,33}$ is dictated by the length scales set by the chain contour and the energy scales determined by the immiscible blocks, with subtle competitions among these length and ener-

gy scales resulting in a wide array of observed morphologies. $^{32,34-36}$

In Figure 1 we illustrate a spectrum of spatial length scales typically important for polymer systems; (i) atomistic structure is foundational to the chemical features and interactions in polymer systems, however these are often coarse-grained to (ii) chain parameters ( $\chi$ parameters, ${ }^{37-43}$ Kuhn length ${ }^{44-46}$ ) that describe an otherwise-featureless polymer chain. ${ }^{15}$ (iii) Local chain conformations and architectural features give rise to overall chain dimensions, ${ }^{47,48}$ and via (iv) interchain interactions lead to self-assembled morphologies such as block copolymers. ${ }^{33,49,50}$ Much of polymer physics revolves around understanding and manipulating these length scales, with a particular focus on universal properties at (or larger than) the chain conformational length scales. ${ }^{31}$ This stems from a desire to understand a wide range of different polymer chemistries with a minimal set of parameters, rather than needing to consider the specific chemistries involved in any polymer chain.

This approach of polymer physics, centering on this hierarchy of length scales, has been remarkably successful; yet, the physics of sequence-defined polymers suggests the presence of another, related hierarchy that - in this viewpoint - we call the sequence-scale $\zeta$. We consider the sequence scale of a sequence-defined polymer to be a characteristic number of monomers along the contour over which the variation of monomer types occurs, in the spirit of blockiness parameters used in the copolymer literature. ${ }^{51}$ We suggest $\zeta$ as an illustrative concept rather than a rigorously defined quantity; for example, an alternating copolymer would have a sequence scale $\zeta \sim$ $\mathcal{O}(1)$ while for a diblock copolymer $\zeta \sim \mathcal{O}(N)$ (where $N$ is the degree of polymerization). The nascent field of sequencedefined polymer physics is just beginning to reckon with the $\zeta$ hierarchy, which we also illustrate in Figure 1 with a direct comparison to the length-scale hierarchy. At the level of atomistic resolution $\zeta \sim 1$, the identity and structure of a given monomer are jointly defined. With increasing $\zeta \approx 1-5$, the sequence scale is on the order of a few monomers and couples, for example, to the Kuhn segment orientation. Larger values of $\zeta \approx 5-20$ begin to exhibit behaviors associated with 'multiblock' copolymers, affecting the local chain conformation or chain-chain interactions. Finally, $\zeta \sim N$ represents the block copolymer limit, where sequence variations drive self-assembly into microphase separated structures.

The juxtaposition of sequence-scale and length-scale hierarchies underscores the major questions of sequence-defined polymers for the polymer physics communities:

(1) To what extent does sequence 'matter' for material properties? At the onset, we should determine if the added challenge of synthesizing sequence-defined polymers is worth the benefits for unique material design.

(2) How does the sequence scale relate to length scale? Of particular concern is how sequence information at small $\zeta$ could give rise to effects at large length scales. Are there fundamental limits associated with how sequence can govern structure and vice versa? Relatedly, how do we effectively measure experimentally, and predict with computation and theory, effects that span multiple length and sequence scales?

(3) How do we consider a vast sequence parameter space? We need strategies to explore the nearly-infinite number of 
possible sequences efficiently. This challenge is further compounded by the need to consider sequence dispersity.

In essence, these are familiar problems when restricted to simply the 'length scale' challenges in polymer systems; yet, they will require additional techniques and physical principles that can account for true along-the-backbone sequence effects.

\section{Does Sequence Matter?}

The exploration of sequence space has, for the most part, been approached from its limiting cases; variations on block copolymers (the large- $\zeta$ limit) and alternating or random copolymers (the small- $\zeta$ limit) have long been considered in the pursuit of new material properties. For the former, gradient and tapered copolymers represent sequence definition at the large- $\zeta$ limit, ${ }^{52-62}$ and are synthesized by statistical copolymer- ization of two or more monomers at a proportion that varies at a defined extent over a defined portion of the chain. ${ }^{58,63}$ These perturbations from standard block copolymers have been extensively studied as a way to modify phase diagram boundaries in a controlled fashion, as the large- $\zeta$ sequence resolution becomes commensurate with the associated microphaseseparated length scales. ${ }^{54,56,59,64}$ At the small- $\zeta$ limit, the study of random copolymers has explored how random sequences may lead to the emergence of microphase separated structures or affect polymer miscibility. ${ }^{51,65-81}$ This is a traditional way of imbuing a polymer material with the advantageous properties of two monomer chemistries. ${ }^{37}$ Theory often relates these local sequence effects to effective interaction parameters or other local physical parameters. ${ }^{73-76}$ a)

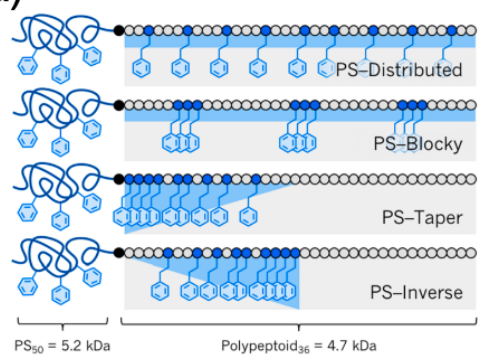

d)

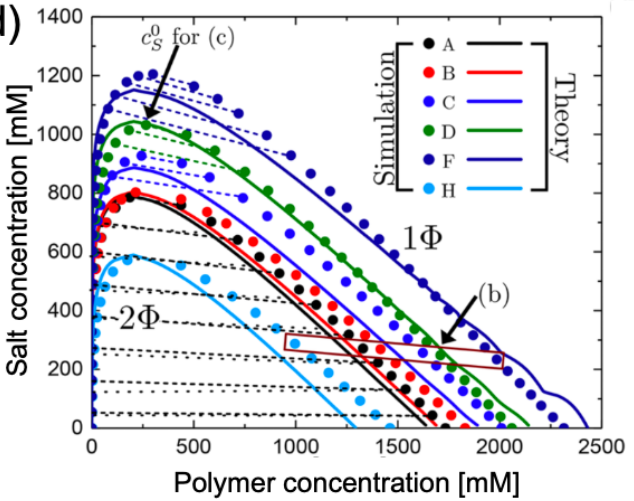

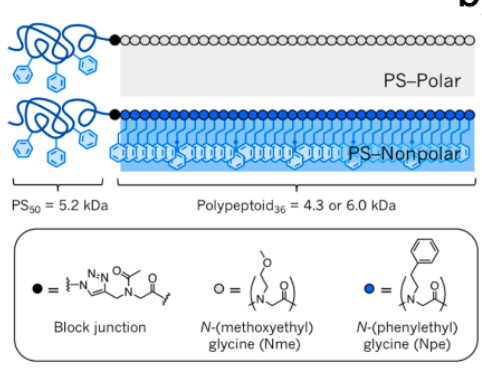

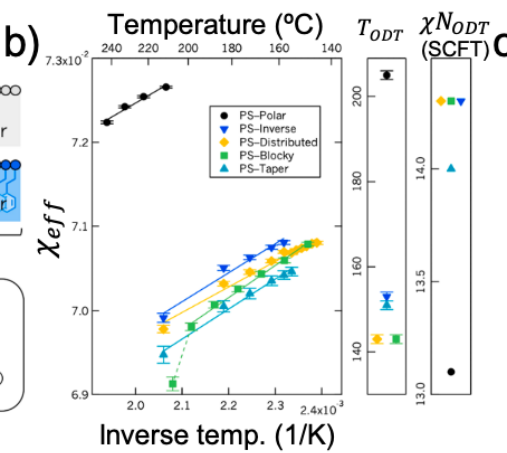

e)

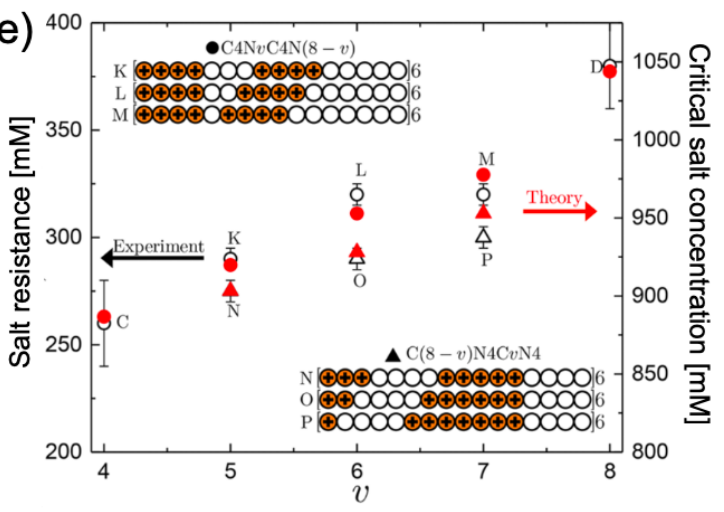

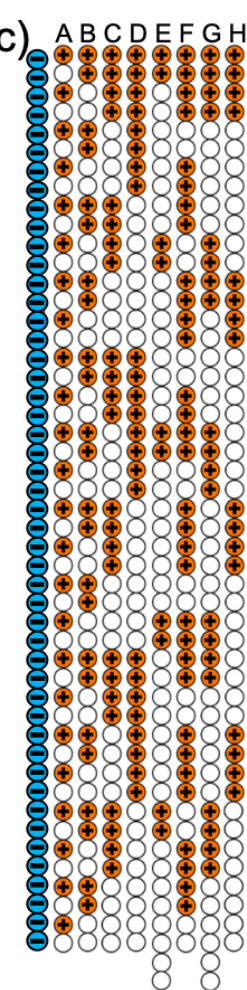

Figure 2: Physical effects from subtle sequence variation. (a) The inclusion of non-polar monomers into a diblock copolymer can be performed in a sequence-defined fashion using solid-phase peptoid synthesis. ${ }^{82}$ (b) The $\chi_{\text {eff }}$ can be determined by scattering via fits to the scattering function predicted by RPA, ${ }^{49}$ but this is inconsistent with the experimentally-measured $T_{O D T} \cdot{ }^{82}$ Both are also inconsistent with self-consistent field theory (SCFT) predictions for the $\chi N_{O D T}$, suggesting physical phenomena due to subtle sequence effects. Reprinted with permission from Patterson, A.L., et al. Macromolecules, 2019, 52, 1277-1286. https://doi.org/10.1021/acs.macromol.8b02298. Copyright 2019 American Chemical Society. (c) Sequence effects have also been studied via the copolymerization of positively-charged and neutral amino acids in peptide synthesis, ${ }^{83}$ in the context of complex coacervation with a homopolyanion. ${ }^{84,85}$ (d) Select sequences in (c) exhibit significantly different phase diagrams, predicted consistently from theory and simulation, sensitive to both the fraction of charged monomers and average block length. ${ }^{84}$ (e) Even small monomer-level variations in sequence at the same charge monomer fraction and average block length exhibit changes in the experimental salt resistance (Perry) and the theoretical critical salt concentration (Sing).$^{84}$ Reprinted with permission from Lytle, et al. ACS Central Science, 2019, 5, 709-718. https://doi.org/10.1021/acscentsci.9b00087. Copyright 2019 American Chemical Society.

These examples underscore a major challenge, however, to determining the importance of sequence; namely, statistical variations of standard copolymer types lead to perturbative differences in material properties at commensurate length scales (i.e., modified phase diagrams, ${ }^{56,59,64}$ effective $\chi$-parameters $\left.{ }^{73-76}\right)$. It remains unclear when the precision of sequence-defined polymers provides access to unique or emergent properties or physical ideas. The salient question that must be addressed is, can the properties of a sequence- defined polymer be retained by substituting a statistical copolymer? For example, the unique properties of tapered polymers emerge from the definition of a region of tapering and the rate of change in the copolymer composition. ${ }^{55,58,60,63}$ In this sense, sequence definition is only relevant at large- $\zeta$, and correspondingly connected to standard descriptors (e.g., blockiness, average monomer fraction) that polymer physics is well-equipped to characterize and predict. 
To contrast, we highlight two recent cases where low- $\zeta$ features lead to non-trivial physical properties: block copolymers with sequence-defined blocks and sequence-defined polyelectrolytes. Patterson et al. ${ }^{82}$ used solid-phase peptoid synthesis to examine the effect of a sequence-defined block on the order-disorder transition (ODT) in block copolymer self-assembly. Polymers with different monomer sequences exhibited qualitatively different behaviors than predicted from standard field theory methods, including the effective $\chi$-parameter determined from the random phase approximation (RPA). ${ }^{49,82}$ This represents a breakdown in established polymer physics tools, due to the presence of a defined chemical sequence (shown in Figure 2a,b). This establishes a key tension of sequence-defined systems, in that large- $\zeta$ effects (i.e., block copolymer micro-phase separation) are influenced in non-trivial ways by small- $\zeta$ features. This type of competition is also at play in some charged systems, such as in electrostatically-driven phase separation (a phenomena known as complex coacervation) ${ }^{86,87}$ studied by Perry and Sing. ${ }^{84,85,88}$ In this situation, even subtle changes in monomer sequence - studied in sequence-defined polypeptides - can lead to significant changes in polymer phase behavior. A variety of polycation sequences (Figure 2c) were mixed with polyanions; simulation and theory consistently predict salt and polyelectrolyte concentrations where phase-separation occurs (Figure 2d, 2 $\Phi$ ) for these sequences. Experiments measured the phase boundary via turbidity, matching the salt concentration where miscibility occurs with theory predictions (Figure 2e); significant differences were observed even for sequences with similar values for common variables such as blockiness and monomer composition. ${ }^{84}$

It remains unclear how these situations arise where sequence scales affect dissimilar length scales, and this open question embodies the potential opportunities in this emerging field of sequence-defined polymers. This is, in our opinion, the foundational aspiration; how can we propagate the information engineered in monomer sequences to yield new and interesting material properties?

\section{Bridging Physical Length and Sequence Scales}

Propagating the information in monomer sequences will require the development of new tools in polymer physics, especially in theory/simulation and in experimental characterization, in addition to nurturing effective collaborations with the synthetic chemists working to increase sequence precision. A primary challenge is to probe the disparate length and sequence scales relevant for these investigations.

Experimental study of sequence-defined polymers requires, first and foremost, the synthesis of these molecules. While polymer chemists have greatly expanded the palette of sequence-defined systems, we note that experimental polymer physicists will more likely be reliant on commercial techniques such as solid-phase synthesis ${ }^{89,90}$ for polypeptides $^{83,91}$ and polypeptoids, ${ }^{92}$ or other automated approaches that can allow for combinatoric synthesis., ${ }^{6,1693}$ The advantage of these approaches is that it allows for reliable synthesis of molecules with monomer-level differences, however it does so at the expense of the length of the polymer molecule and the scale of the synthesis. Alternatively, biosynthesis can lead to polymers that are significantly longer but still sequence-defined; ${ }^{94,95}$ however, biological constraints limits the chemistry and regularity of the sequences considered. There may also be promise in recently-reported meth- ods for using modular assembly ${ }^{96}$ or automation ${ }^{61,62,93}$ to realize sequence on larger macromonomer length scales.
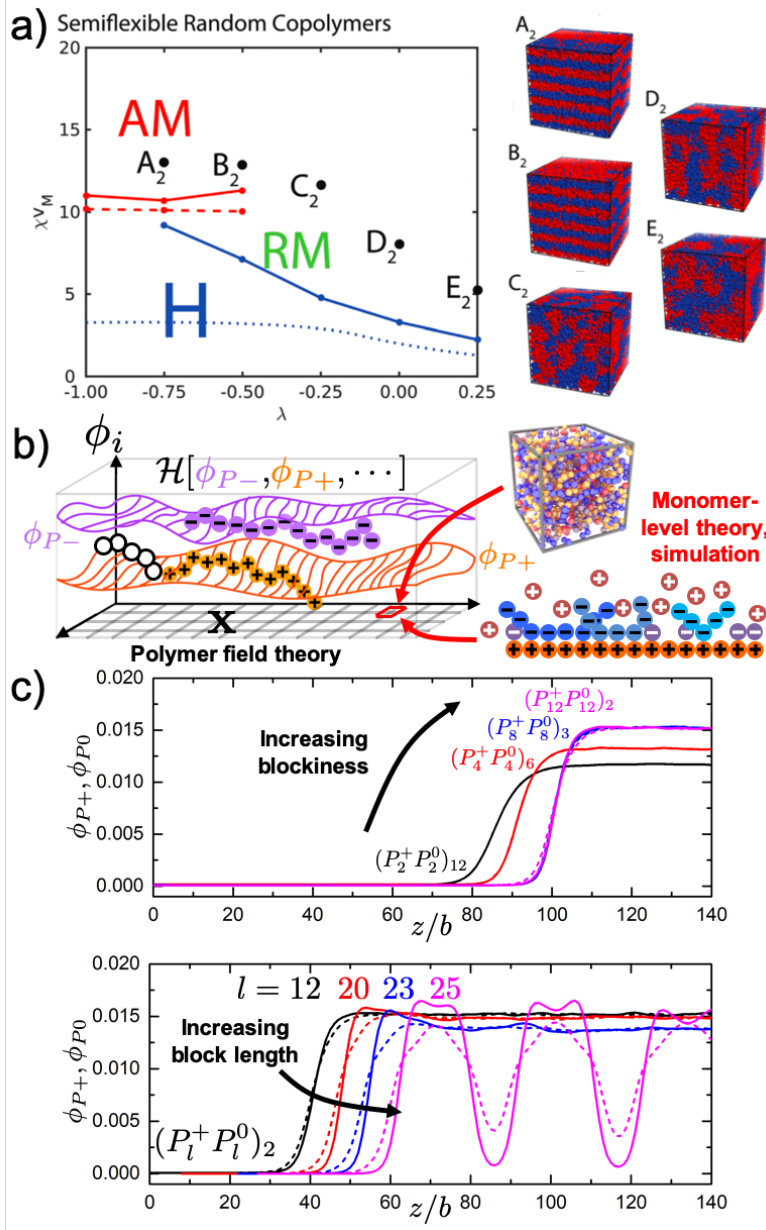

Figure 3: Bridging Length Scales. (a) SCMF calculations by Mao et al. capture how microphase separation emerges from molecular detail in semiflexible random copolymers. ${ }^{97}$ Phase behavior is a function of $\chi$ and a sequence parameter $\lambda(\lambda=-1$ is alternating, $\lambda=0$ is random, $\lambda \rightarrow 1$ is increasingly blocky), ranging from homogeneous $(\mathrm{H})$, aligned mesophase separation $(\mathrm{AM})$, and random mesophase separation (RM); these regions change with molecular stiffness. ${ }^{97,98}$ Adapted from Mao, et al. Soft Matter, 2017, 13, 2760-2772. https://doi.org/10.1039/C7SM00164A. Reproduced by permission of The Royal Society of Chemistry. (b) Sing has developed hybrid methods to bridge between local, monomer-level information into polymer field theory and molecular selfassembly..$^{99-102}$ The schematic illustrates polymer field theory (left), which maps a multi-chain system to single chains in a 'field' of neighbor densities $\phi$ with a Hamiltonian $\mathcal{H}$; at each field location $\boldsymbol{x}$, thermodynamic information can be included from simulation or theory (snapshot and schematic shown). ${ }^{99,103}$ (c) This method can capture how charge-driven phase separation is affected by the presence of a sequence-defined polycation, upon increasing blockiness while keeping chain length the same, (a local sequence effect, top) ${ }^{84,85,99}$ It can also predict the emergence of self-assembled structures, by changing the block length for tetrablock polymers (a non-local sequence effect, bottom) ${ }^{99}$ Graphs plot species density $\phi_{P+}$ and $\phi_{0}$ (for cationic and neutral monomers respectively) over a spatial dimension $z / b$. Reprinted from Sing, C.E. J. Chem. Phys., 2020, 152, 024902. https://doi.org/10.1063/1.5140756. 
Current approaches to characterize these materials remain standard, indirect, and thus require inference of the effect of monomer-level changes on sequence. These include the use of X-ray and neutron scattering, bulk phase separation, and calorimetry. It is worth noting that such methods can be powerful, especially to understand monomer-scale sequencedefined polymers that undergo ordering via crystallization, ${ }^{104,105}$ yet all of these methods capture ensemble averages rather than single-chain properties. This is an area where efforts to co-opt biophysical tools represent a promising route to understanding the role of sequence; in particular, fluorescence measurements have begun to play a key role in a number of polymer measurements ${ }^{106-111}$ in a way that may be readily utilized for sequence-defined polymers to probe structural position and dynamics and possibly looking at specific monomers. While the promise of single-molecule measurements develops, most methods will rely on the connection between sequence-defined perturbations and observable, averaged properties that must be interpreted through molecular theory and simulation.

Bridging length/time scales is not a new paradigm for those in the computational and theoretical research space, where coarse-graining ${ }^{112}$ is regularly used to extend beyond the limitations of standard methods. However, this is an existential necessity for the study of sequence-defined polymers; useful tools for predicting and understanding these systems require a reconciliation of both the local, monomer-level sequence behavior and macroscopic or mesoscale observables. In particular, a number of efforts have pushed the bounds of field theoretic techniques; for example, a number of RPA theoretical models have been developed to predict sequence effects - for both specific and random sequences in coacervation. ${ }^{113-115}$ This class of theoretical model has found some success in reproducing trends, ${ }^{114,116}$ yet is known to neglect important molecular correlations and often fails in sequence-defined situations. Complex Langevin (i.e., numerical field theory) calculations can address the limitations of RPA, ${ }^{117}$ and has also been used to consider sequencespecificity in charged polymer phase behavior. ${ }^{118-120}$ However, all of these approaches rely on coarse-grained chain representations (e.g., Gaussian segments) that do not fully resolve the packing and organization of monomer sequences. Related single-chain in mean field (SCMF) simulations have demonstrated the importance of addressing these limitations for copolymers, ${ }^{121-123}$ for example showing that semiflexible random copolymers exhibit non-trivial phase behavior due to how molecular packing and monomer-level structure relate to monomer sequence (Figure 3a). ${ }^{97,98,124}$

There is evidence that detailed models, that specifically resolve monomer length-scales, are indeed a crucial aspect for studying sequence-defined polymers. Particle-based computational models have demonstrated sequence-specific effects in compatibilization, ${ }^{125}$ where highly non-regular sequences decrease the interfacial tension between two species beyond regular blocky or alternating sequences. Polyelectrolyte and polyampholyte complexation is also highly sensitive to sequence, ${ }^{126,127}$ which may be crucial to the formation of drug-delivering polyplexes. The authors have used particle-based simulations to study complex coacervation for a wide range of polyelectrolyte sequences, ${ }^{84,85}$ which also inform theories that specifically consider how local correlations arising from charge packing and charged-monomer sequence govern phase behavior (Figure 3b,c).$^{84,88,99,100}$ Our view is that the theoretical and computational study of sequence-defined polymers must take advantage of the full suite of computational and theoretical tools, connecting the monomer-level resolution inherent to particle-based methods to larger length-scale methods, such as field theory, that can be used to determine polymer morphology and structure.
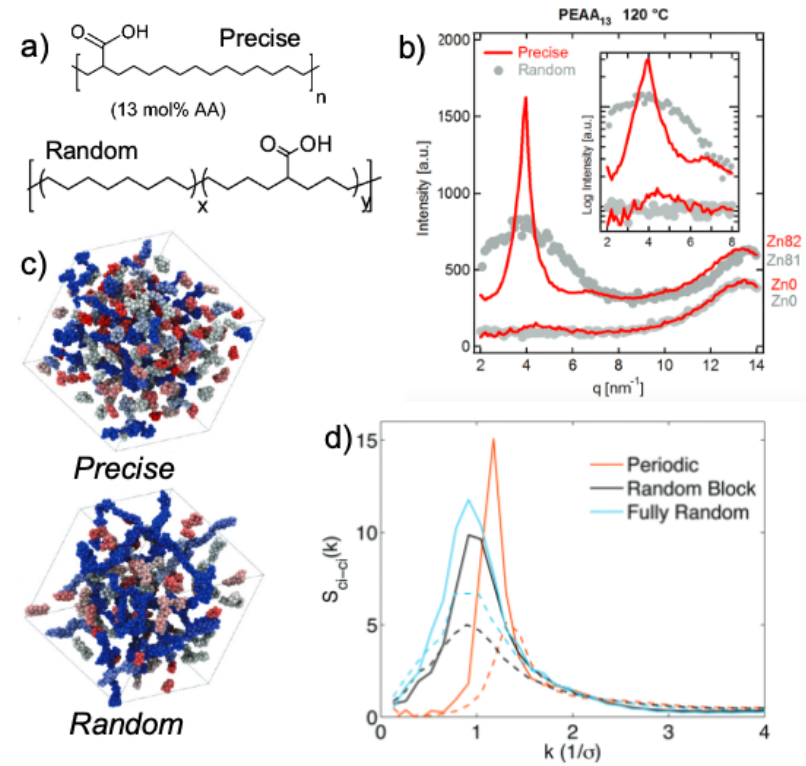

Figure 4: Sequence-defined polymers require close collaboration among polymer science disciplines. Sequencedefinition plays a key role in the material properties of precise ionomers. Here, materials synthesized by Wagener (a) were characterized via X-ray scattering by Winey ${ }^{130}$ (b) to show how precise monomer sequence leads to well-defined structural features (i.e., ion clusters). (a) is reprinted with permission from Baughman, et al. Macromolecules, 2007, 40, 6564-6571. https://doi.org/10.1021/ma070841r. Copyright 2007 American Chemical Society. (b) is reprinted with permission from Seitz, et al. J. Am. Chem. Soc., 2010, 132, 8165-8174. https://doi.org/10.1021/ja101991d. Copyright 2010 American Chemical Society. Molecular simulation (c) from Hall and Frischknecht ${ }^{131-133}$ provides a glimpse at the distribution of ion clusters to provide context for - and matching with - the averaged ion-ion scattering function $S_{C l-C l}(k)$. (d). Reprinted with permission from Hall, et al. J. Am. Chem. Soc., 2012, 134, 574587. https://doi.org/10.1021/ja209142b. Copyright 2012 American Chemical Society.

In a similar spirit, integration of theory/simulation, characterization, and synthesis is crucial to (i) interpret experimental results based on ensemble averaged quantities and (ii) refine the approximations that must be made to account for disparate length/sequence scales. Indeed, most successful efforts in sequence-defined polymers consist of all three; for example, sequence-precise ionomers synthesized by the Wagener group, ${ }^{128,129}$ characterized by the Winey group, ${ }^{130}$ and studied via simulation by Frischknecht and Hall, ${ }^{131-133}$ have demonstrated the importance of monomer-level spacing on the structural and dynamic properties of ion conducting ionomers (Figure 4). Analogous examples, such as sequence-defined polypeptides or polypeptoids, ${ }^{134,135}$ protein environments, ${ }^{136}$ synthetic oligomer solution structure, ${ }^{137}$ and polyelectrolyte phase behavior ${ }^{84,85,88,138}$ highlight the progress that can be made when theorists, polymer chemists, and polymer engineers work together. 


\section{Sequence Information - Design in a Vast Parameter Space}

Utilizing sequence-defined polymers will require advances in how we consider the vast parameter space of monomer sequence, where the number of permutations for a copolymer of only two monomers is $\mathcal{O}\left(2^{N}\right)$, yet $N$ is often large and more monomer types can be considered. Advances in machine learning and other sophisticated data science techniques ${ }^{139,140}$ for exploring this space enable the engineering of molecules, complementary with other physics-motivated concepts. Here is another area where borrowing tools from the biophysical protein-folding community will yield new insights, in particular in the use of machine learning and high throughput experiments to augment the role of fundamental theory, simulation, and materials characterization. Meenakshisundaram et al. provide an example of this sort of study, ${ }^{125}$ using genetic algorithms to determine optimal monomer sequences for copolymer compatibilizers; the surprising result being a highly irregular sequence that would likely not have been otherwise predicted (Figure 5a). This combinatorial approach suggests non-trivial physical phenomena are at play, highlighting places in the vast sequence parameter space where more standard theory could focus its efforts to yield explanations.
In addition to combinatorial machine learning techniques, it is possible to leverage 'physics-motivated' concepts for sequence design. For example, historical efforts to model or emulate proteins via the collapse $\mathrm{s}^{27,141-143}$ or surfaceadsorption $^{144-147}$ of hydrophobic/hydrophilic (HP) sequences $^{148}$ suggested the design of sequence by tuning monomer sequence as to maximize the stability of a prefolded/adsorbed conformation (Figure 5b,c) ${ }^{142}$ This scheme has been realized experimentally, ${ }^{149}$ showing that irregular 'protein-like' sequences can exhibit markedly different behaviors during a coil-collapse transition (Figure 5d).

These advances in sequence design face the same challenges that affect the fundamental prediction and characterization of sequence-defined polymers, in that it is unclear how these methods will extend to design across length and sequence scales. The tools of machine learning and physical design schemes must contend with both self-interactions (the focus of e.g., model polymer collapse) and intermolecular interactions that may form structures analogous to the tertiary and quaternary structures in proteins. The challenge is thus - once there is a physical basis for bridging $\zeta$-scales to develop strategies to explore an expanded sequence space enriched by the presence of many molecules.
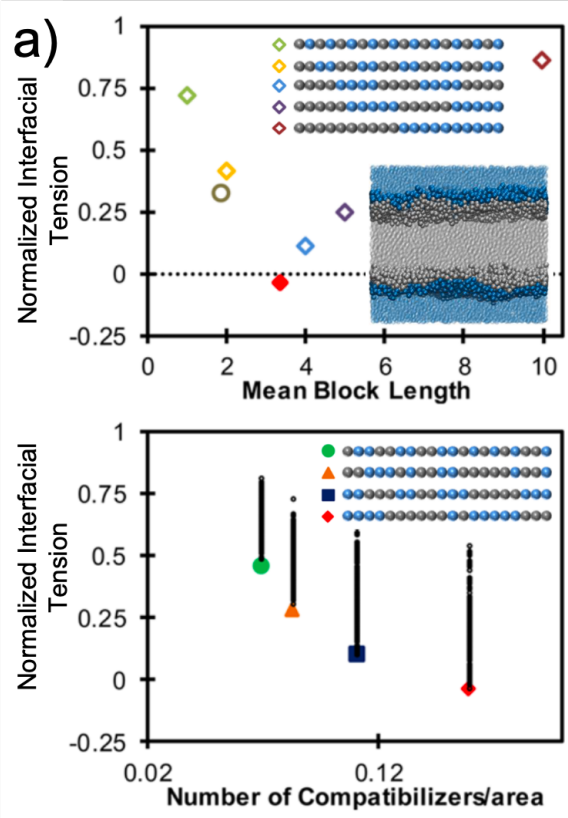

b)
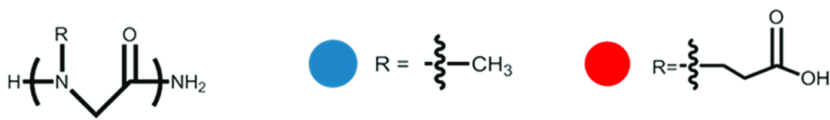
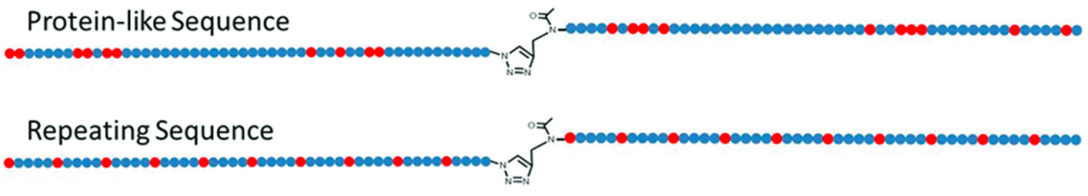

c)

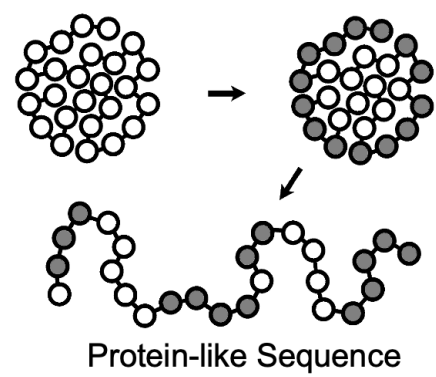

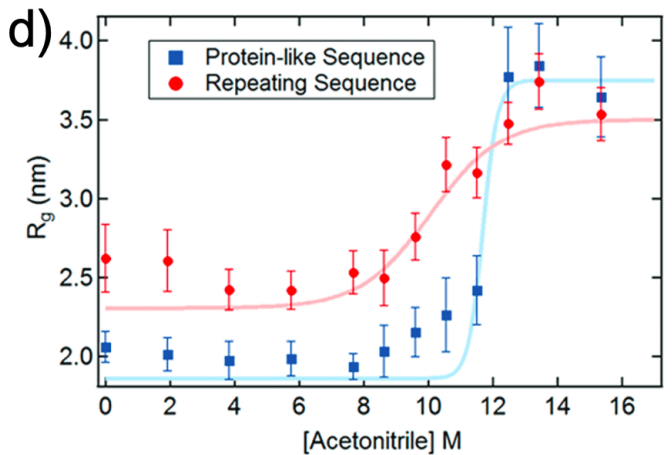

Figure 5: Sequence Design. (a) Meenakshisundaram et al. used a genetic algorithm to determine optimal sequences for compatibilization of binary polymer blend interfaces, evaluated via the interfacial tension. ${ }^{125}$ The optimal sequence performed distinctly better than regular blocks (open symbols, top), and depended on the compatibilizer concentration (bottom). ${ }^{125}$ Reprinted with permission from Meenakshisundaram, et al. Macromolecules, 2017, 50, 1155-1166. https://doi.org/10.1021/acs.macromol.6b01747. Copyright 2017 American Chemical Society. (b) Irregular sequences were also found to promote polymer collapse compared to repeating sequences in hydrophilic/hydrophobic (HP) model polymers, ${ }^{141,142,148,149}$ with sequences determined by decorating the outside of a pre-collapsed globule (c). Reprinted figure with permission from Khoklov, A.R. and Khalatur, P.G. Phys. Rev. Lett., 82, 3456-3459, 1999. https://doi.org/10.1103/PhysRevLett.82.3456. Copyright 1999 by the American Physical Society. (d) This designed sequence exhibited a sharper collapse transition, a 'protein-like' behavior. ${ }^{149}$ Reprinted with permission from Murnen, et al. Macromolecules, 2012, 45, 52295236. https://doi.org/10.1021/ma300707t. Copyright 2012 American Chemical Society.

\section{Sequence precision: How good is good enough?}

The further development of the design, characterization, and prediction of sequence-defined polymers must finally contend with a major question at the intersection of fundamental polymer physics and chemistry, and the practical application of sequence-defined polymers to materials; how much precision is necessary to observe changes in properties? ${ }^{150}$ This is especially important at the small- $\zeta$ limit, where sequence-dispersity may have a pronounced effect. Yet, in situations where small- $\zeta$ sequence-effects propagate to larger length scales, this becomes a challenging and im- 
portant question. However, theoretical efforts on random copolymers only hint at the role of this dispersity, and even the language of sequence errors/dispersity is not yet developed; how do we measure, characterize, and predict these type of dispersity effects? We note that, as the physics of sequence-defined polymers gets increasingly specific to the precisely encoded information, in contrast to collective descriptors, it is likely that the types of sequence errors will not be adequately described by single quantitative metrics.

\section{Conclusion}

The scope of questions related to sequence-defined polymers remain extremely broad, and we think this represents a key area where the next century of polymer science is poised to make significant progress. While enabled by advanced methods and tools - automated synthesis, machine learning algorithms and computational power, and increasinglysophisticated characterization - the current knowledge of polymer science provides a foundation to study this problem with a unique perspective that complements our neighboring disciplines (e.g., biophysics, colloidal science). However, the ability of the polymer community to take advantage of this opportunity to explore a rich, new world of sequence-defined polymers will be contingent on the development and nurturing of close connections between experimental and theoretical polymer physicists, and those at the forefront of polymer synthesis.

\section{AUTHOR INFORMATION}

\section{Corresponding Author}

$\dagger$ E-mail: perrys@engin.umass.edu

* E-mail: cesing@,illinois.edu

\section{Author Contributions}

The manuscript was written through contributions of all authors.

\section{Notes}

The authors declare no competing financial interest.

\section{ACKNOWLEDGMENT}

C.E.S acknowledges support from NSF CAREER Award DMR1654158. S.L.P. acknowledges support from the National Science Foundation under NSF CBET-1804177 and CMMI1727660

\section{REFERENCES}

(1) Lutz, J.-F. Aperiodic Copolymers. ACS Macro Lett. 2014, 3 (10), 1020-1023. https://doi.org/10.1021/mz5004823.

(2) Rowan, S. J.; Barner-Kowollik, C.; Klumperman, B.; Gaspard, P.; Grubbs, R. B.; Hillmyer, M. A.; Hutchings, L. R.; Mahanthappa, M. K.; Moatsou, D.; O'Reilly, R. K.; Ouchi, M.; Sawamoto, M.; Lodge, T.P. Discussion on "Aperiodic Copolymers." ACS Macro Lett. 2016, 5 (1), 1-3. https://doi.org/10.1021/acsmacrolett.5b00758.

(3) Lutz, J.-F. Defining the Field of Sequence-Controlled Polymers. Macromol. Rapid Commun. 2017, 38 (24), 1700582. https://doi.org/10.1002/marc.201700582.

(4) Badi, N.; Lutz, J.-F. Sequence Control in Polymer Synthesis. Chem. Soc. Rev. 2009, 38 (12), 3383. https://doi.org/10.1039/b806413j.

(5) Lutz, J. F.; Ouchi, M.; Liu, D. R.; Sawamoto, M. Sequence-Controlled Polymers. Science 2013, 341, 1238149.

(6) Lutz, J. F.; Lehn, J. M.; Meijer, E. W.; Matyjaszewski, K. From Precision Polymers to Complex Materials and Systems. Nat Rev Mater 2016, 1, 1-14.
(7) Bates, F. S.; Hillmyer, M. A.; Lodge, T. P.; Bates, C. M.; Delaney, K. T.; Fredrickson, G. H. Multiblock Polymers: Panacea or Pandora's Box. Science 2012, 336, 434-440.

(8) Barnes, J. C.; Ehrlich, D. J. C.; Gao, A. X.; Leibfarth, F. A.; Jiang, Y.; Zhou, E.; Jamison, T. F.; Johnson, J. A. Iterative Exponential Growth of Stereo- and Sequence-Controlled Polymers. Nat Chem 2015, 7, 810-815.

(9) Anastasaki, A.; Nikolaou, V.; Pappas, G. S.; Zhang, Q.; Wan, C.; Wilson, P.; Davis, T. P.; Whittaker, M. R.; Haddleton, D. M. Photoinduced Sequence-Control via One Pot Living Radical Polymerization of Acrylates. Chem Sci 2014, 5 (9), 3536-3542. https://doi.org/10.1039/C4SC01374C.

(10) Solleder, S. C.; Zengel, D.; Wetzel, K. S.; Meier, M. A. R. A Scalable and High-Yield Strategy for the Synthesis of Sequence-Defined Macromolecules. Angew. Chem. Int Ed 2016, 55, 1204-1207.

(11) Solleder, S. C.; Schneider, R. V.; Wetzel, K. S.; Boukis, A. C.; Meier, M. A. R. Recent Progress in the Design of Monodisperse, Sequence-Defined Macromolecules. Macromol. Rapid Com$\begin{array}{llll}\text { mun. } & \mathbf{2 0 1 7}, & 38 & \text { (9), }\end{array}$ https://doi.org/10.1002/marc.201600711.

(12) Soeriyadi, A. H.; Boyer, C.; Nyström, F.; Zetterlund, P. B.; Whittaker, M. R. High-Order Multiblock Copolymers via Iterative $\mathrm{Cu}(0)$-Mediated Radical Polymerizations (SET-LRP): Toward Biological Precision. J. Am. Chem. Soc. 2011, 133 (29), 1112811131. https://doi.org/10.1021/ja205080u.

(13) Moatsou, D.; Hansell, C. F.; O’Reilly, R. K. Precision Polymers: A Kinetic Approach for Functional Poly(Norbornenes). Chem Sci 2014, 5 (6), 2246-2250. https://doi.org/10.1039/C4SC00752B.

(14) Ring, W.; Mita, I.; Jenkins, A. D.; Bikales, N. M. SourceBased Nomenclature for Copolymers. Pure Appl Chem 1985, 57, 1427.

(15) Rubinstein, M.; Colby, R. Polymer Physics; Oxford University Press, N. Y., 2003.

(16) Lutz, J.-F. Coding Macromolecules: Inputting Information in Polymers Using Monomer-Based Alphabets. Macromole$\begin{array}{lllll}\text { cules } & \mathbf{2 0 1 5}, & 48 & \text { (14), } & \text { 4759-4767. }\end{array}$ https://doi.org/10.1021/acs.macromol.5b00890.

(17) Austin, M. J.; Rosales, A. M. Tunable Biomaterials from Synthetic, Sequence-Controlled Polymers. Biomater. Sci. 2019, 7 (2), 490-505. https://doi.org/10.1039/C8BM01215F.

(18) Phan, N. N.; Li, C.; Alabi, C. A. Intracellular Delivery via Noncharged Sequence-Defined Cell-Penetrating Oligomers. Bioconjug. Chem. 2018, 29 (8), 2628-2635. https://doi.org/10.1021/acs.bioconjchem.8b00336.

(19) Gerke, C.; Jacobi, F.; Goodwin, L. E.; Pieper, F.; Schmidt, S.; Hartmann, L. Sequence-Controlled High Molecular Weight Glyco(Oligoamide)-PEG Multiblock Copolymers as Ligands and Inhibitors in Lectin Binding. Macromolecules 2018, 51 (15), 5608-5619. https://doi.org/10.1021/acs.macromol.8b00982.

(20) Washington, M. A.; Balmert, S. C.; Fedorchak, M. V.; Little, S. R.; Watkins, S. C.; Meyer, T. Y. Monomer Sequence in PLGA Microparticles: Effects on Acidic Microclimates and in Vivo Inflammatory Response. Acta Biomater. 2018, 65, 259-271. https://doi.org/10.1016/j.actbio.2017.10.043.

(21) Castro, C. E.; Kilchherr, F.; Kim, D.-N.; Shiao, E. L.; Wauer, T.; Wortmann, P.; Bathe, M.; Dietz, H. A Primer to Scaffolded DNA Origami. Nat. Methods 2011, 8 (3), 221-229. https://doi.org/10.1038/nmeth.1570.

(22) Church, G. M.; Gao, Y.; Kosuri, S. Next-Generation Digital Information Storage in DNA. Science 2012, 337 (6102), 1628 1628. https://doi.org/10.1126/science.1226355.

(23) Sim, A. Y.; Minary, P.; Levitt, M. Modeling Nucleic Acids. Curr. Opin. Struct. Biol. 2012, 22 (3), 273-278. https://doi.org/10.1016/j.sbi.2012.03.012.

(24) Laing, C.; Schlick, T. Computational Approaches to RNA Structure Prediction, Analysis, and Design. Curr. Opin. Struct. Biol. 2011, 21 (3), 306-318. https://doi.org/10.1016/j.sbi.2011.03.015. 
(25) Onuchic, J. N.; Luthey-Schulten, Z.; Wolynes, P. G. Theory of Protein Folding: The Energy Landscape Perspective. Annu. Rev. Phys. Chem. 1997, 48 (1), 545-600. https://doi.org/10.1146/annurev.physchem.48.1.545.

(26) Dill, K. A.; Chan, H. S. From Levinthal to Pathways to Funnels. Nat. Struct. Mol. Biol. 1997, 4 (1), 10-19. https://doi.org/10.1038/nsb0197-10.

(27) Dill, K. A.; Bromberg, S.; Yue, K.; Chan, H. S.; Ftebig, K. M.; Yee, D. P.; Thomas, P. D. Principles of Protein Folding - A Perspective from Simple Exact Models. Protein Sci. 2008, 4 (4), 561-602. https://doi.org/10.1002/pro.5560040401.

(28) Karplus, M.; McCammon, J. A. Molecular Dynamics Simulations of Biomolecules. Nat. Struct. Biol. 2002, 9 (9), 7.

(29) Wright, P. E.; Dyson, H. J. Intrinsically Unstructured Proteins: Re-Assessing the Protein Structure-Function Paradigm. $J$ Mol Biol 1999, $293 \quad$ (2), https://doi.org/10.1006/jmbi.1999.3110.

(30) Uversky, V. N.; Kuznetsova, I. M.; Turoverov, K. K.; Zaslavsky, B. Intrinsically Disordered Proteins as Crucial Constituents of Cellular Aqueous Two Phase Systems and Coacervates. FEBS Lett 2015, 589 (1), 15-22. https://doi.org/10.1016/j.febslet.2014.11.028.

(31) de Gennes, P.-G. Scaling Concepts in Polymer Physics; Cornell University Press, 1979.

(32) Bates, C. M.; Bates, F. S. 50th Anniversary Perspective: Block Polymers-Pure Potential. Macromolecules 2017, 50 (1), 322. https://doi.org/10.1021/acs.macromol.6b02355.

(33) Bates, F. S.; Fredrickson, G. H. Block Copolymer Thermodynamics: Theory and Experiment. Annu Rev Phys Chem 1990, $41,525-557$.

(34) Lee, S.; Bluemle, M. J.; Bates, F. S. Discovery of a Frank-Kasper Sigma Phase in Sphere-Forming Block Copolymer Melts. Science 2010, 330, 349-353.

(35) Gillard, T. M.; Lee, S.; Bates, F. S. Dodecagonal Quasicrystalline Order in a Diblock Copolymer Melt. Proc. Natl. Acad. Sci. 2016, 113 (19), 5167-5172. https://doi.org/10.1073/pnas.1601692113.

(36) Hajduk, D. A.; Harper, P. E.; Gruner, S. M.; Honeker, C. C.; Kim, G.; Thomas, E. L.; Fetters, L. J. The Gyroid: A New Equilibrium Morphology in Weakly Segregated Diblock Copolymers. Macromolecules 1994, $27 \quad$ (15), 4063-4075. https://doi.org/10.1021/ma00093a006.

(37) Flory, P. J. Principles of Polymer Chemistry; Cornell University Press: Ithaca, NY, 1953.

(38) Curro, J. G.; Schweizer, K. S. Theory for the Chi Parameter of Polymer Blends: Effect of Attractive Interactions. $J$. Chem. Phys. 1988, $88 \quad$ (11), 7242-7243. https://doi.org/10.1063/1.454377.

(39) Cherayil, B. J.; Freed, K. F. The Flory .Chi. Parameter and Phase Separation in Semidilute Polymer Mixtures: A Renormalization Group Study. Macromolecules 1988, 21 (11), 3204-3216. https://doi.org/10.1021/ma00189a014.

(40) Dudowicz, J.; Freed, K. F. Relation of Effective Interaction Parameters for Binary Blends and Diblock Copolymers: Lattice Cluster Theory Predictions and Comparisons with Experiment. Macromolecules 1993, 26, 213-220.

(41) Zhang, W.; Gomez, E. D.; Milner, S. T. Predicting FloryHuggins $\chi$ from Simulations. Phys. Rev. Lett. 2017, 119 (1), 017801. https://doi.org/10.1103/PhysRevLett.119.017801.

(42) Chen, Q. P.; Xie, S.; Foudazi, R.; Lodge, T. P.; Siepmann, J. I. Understanding the Molecular Weight Dependence of $\chi$ and the Effect of Dispersity on Polymer Blend Phase Diagrams. Macromolecules 2018, $51 \quad$ (10), 3774-3787. https://doi.org/10.1021/acs.macromol.8b00604.

(43) Ravichandran, A.; Chen, C.-C.; Khare, R. Prediction of $\chi$ Parameter of Polymer Blends by Combining Molecular Simulations and Integral Equation Theory. J. Phys. Chem. B 2018, 122 (38), 9022-9031. https://doi.org/10.1021/acs.jpcb.8b06684.

(44) Flory, P. J. Statistical Mechanics of Chain Molecules; Wiley: New York, 1969.
(45) Bouchiat, C.; Wang, M. D.; Allemand, J.-F.; Strick, T.; Block, S. M.; Croquette, V. Estimating the Persistence Length of a Worm-Like Chain Molecule from Force-Extension Measurements. Biophys. J. 1999, 76 (1), 409-413. https://doi.org/10.1016/S00063495(99)77207-3.

(46) Hays, J. B.; Magar, M. E.; Zimm, B. H. Persistence Length of DNA. Biopolymers 1969, 8 (4), 531-536. https://doi.org/10.1002/bip.1969.360080410.

(47) Polymeropoulos, G.; Zapsas, G.; Ntetsikas, K.; Bilalis, P.; Gnanou, Y.; Hadjichristidis, N. 50th Anniversary Perspective: Polymers with Complex Architectures. Macromolecules 2017, 50 (4), 1253-1290. https://doi.org/10.1021/acs.macromol.6b02569.

(48) Wang, Z.-G. 50th Anniversary Perspective: Polymer Conformation-A Pedagogical Review. Macromolecules 2017, 50 (23), 9073-9114. https://doi.org/10.1021/acs.macromol.7b01518.

(49) Leibler, L. Theory of Microphase Separation in Block Copolymers. Macromolecules 1980, 13, 1602-1617.

(50) Hu, H.; Gopinadhan, M.; Osuji, C. O. Directed SelfAssembly of Block Copolymers: A Tutorial Review of Strategies for Enabling Nanotechnology with Soft Matter. Soft Matter 2014, 10 (22), 3867. https://doi.org/10.1039/c3sm52607k.

(51) Fredrickson, G. H.; Milner, S. T. Thermodynamics of Random Copolymer Melts. Phys. Rev. Lett. 1991, 67 (7), 835-838. https://doi.org/10.1103/PhysRevLett.67.835.

(52) Beginn, U. Gradient Copolymers. Colloid Polym. Sci. 2008, 286 (13), 1465-1474. https://doi.org/10.1007/s00396-008$1922-y$.

(53) Mok, M. M.; Kim, J.; Torkelson, J. M. Gradient Copolymers with Broad Glass Transition Temperature Regions: Design of Purely Interphase Compositions for Damping Applications. $J$. Polym. Sci. Part B Polym. Phys. 2008, 46 (1), 48-58. https://doi.org/10.1002/polb.21341.

(54) Shull, K. R. Interfacial Activity of Gradient Copolymers. Macromolecules $\quad$ 2002, 35 (22), 8631-8639. https://doi.org/10.1021/ma020698w.

(55) Levine, W. G.; Seo, Y.; Broan, J. R.; Hall, L. M. Effect of Sequence Dispersity on Morphology of Tapered Diblock Copolymers from Molecular Dynamics Simulations. J Chem Phys 2016, $145,234907$.

(56) Lefebvre, M. D.; Olvera de la Cruz, M.; Shull, K. R. Phase Segregation in Gradient Copolymer Melts. Macromolecules 2004, 37 (3), 1118-1123. https://doi.org/10.1021/ma035141a.

(57) Mok, M. M.; Pujari, S.; Burghardt, W. R.; Dettmer, C. M.; Nguyen, S. T.; Ellison, C. J.; Torkelson, J. M. Microphase Separation and Shear Alignment of Gradient Copolymers: Melt Rheology and Small-Angle X-Ray Scattering Analysis. Macromolecules 2008, 41 (15), 5818-5829. https://doi.org/10.1021/ma8009454.

(58) Hodrokoukes, P.; Floudas, G.; Pispas, S.; Hadjichristidis, N. Microphase Separation in Normal and Inverse Tapered Block Copolymers of Polystyrene and Polyisoprene. 1. Phase State. Macromolecules 2001, $34 \quad$ (3), 650-657. https://doi.org/10.1021/ma001479i.

(59) Aksimentiev, A.; Holyst, R. Phase Behavior of Gradient Copolymers. J Chem Phys 1999, 111, 2329-2339.

(60) Singh, N.; Tureau, M. S.; Epps, III, T. H. Manipulating Ordering Transitions in Interfacially Modified Block Copolymers. Soft Matter 2009, 5 (23), 4757. https://doi.org/10.1039/b908739g.

(61) Walsh, D. J.; Guironnet, D. Macromolecules with Programmable Shape, Size, and Chemistry. Proc Natl Acad Sci USA 2019, $116 \quad$ (5), 201817745. https://doi.org/10.1073/pnas.1817745116.

(62) Walsh, D. J.; Dutta, S.; Sing, C. E.; Guironnet, D. Engineering of Molecular Geometry in Bottlebrush Polymers. Macromolecules 2019, $52 \quad$ (13), 4847-4857. https://doi.org/10.1021/acs.macromol.9b00845.

(63) Tsukahara, Y.; Nakamura, N.; Hashimoto, T.; Kawai, H.; Nagaya, T.; Sugimura, Y.; Tsuge, S. Structure and Properties of Tapered Block Polymers of Styrene and Isoprene. Polym. J. 1980, 12 (7), 455-466. https://doi.org/10.1295/polymj.12.455. 
(64) Jiang, R.; Jin, Q.; Li, B.; Ding, D.; Wickham, R. A.; Shi, A.-C. Phase Behavior of Gradient Copolymers. Macromolecules 2008, 41 (14), 5457-5465. https://doi.org/10.1021/ma8002517.

(65) Dobrynin, A. V.; Leibler, L. Theory of Random Copolymers near the Lifshitz Point. Europhys. Lett. EPL 1996, 36 (4), 283 288. https://doi.org/10.1209/epl/i1996-00223-5.

(66) Semenov, A. N.; Likhtman, A. E. Theory of Secondary Domain Structures in Disordered Multiblock Copolymers. Macromolecules $\quad 1998, \quad 31 \quad$ (25), 9058-9071. https://doi.org/10.1021/ma981044j.

(67) von der Heydt, A.; Müller, M.; Zippelius, A. Three-Phase Coexistence with Sequence Partitioning in Symmetric Random Block Copolymers. Phys. Rev. E 2011, 83 (5), 051131. https://doi.org/10.1103/PhysRevE.83.051131.

(68) Sung, B. J.; Yethiraj, A. Integral Equation Theory of Random Copolymer Melts. Macromolecules 2005, 38 (5), 20002008. https://doi.org/10.1021/ma0487195.

(69) Subbotin, A. V.; Semenov, A. N. Phase Equilibria in Random Multiblock Copolymers. Eur. Phys. J. E 2002, 7 (1), 49 64. https://doi.org/10.1140/epje/i200101101.

(70) Dobrynin, A. V. Phase Coexistence in Random Copolymers. J. Chem. Phys. 1997, 107 (21), 9234-9238. https://doi.org/10.1063/1.475215.

(71) Dobrynin, A. V.; Leibler, L. Theory of Polydisperse Multiblock Copolymers. 1997, 30 (16), 10.

(72) Sung, B. J.; Yethiraj, A. Integral Equation Theory of Randomly Coupled Multiblock Copolymer Melts: Effect of Block Size on the Phase Behavior. J. Chem. Phys. 2005, 123 (21), 214901. https://doi.org/10.1063/1.2131057.

(73) Balazs, A. C.; Sanchez, I. C.; Epstein, I. R.; Karasz, F. E.; MacKnight, W. J. Effect of Sequence Distribution on the Miscibility of Polymer/Copolymer Blends. Macromolecules 1985, 18 (11), 2188-2191. https://doi.org/10.1021/ma00153a021.

(74) Balazs, A. C.; Karasz, F. E.; MacKnight, W. J.; Ueda, H.; Sanchez, I. C. Copolymer/Copolymer Blends: Effect of Sequence Distribution on Miscibility. Macromolecules 1985, 18, 2784-2786.

(75) Yeung, C.; Balazs, A. C.; Jasnow, D. Adsorption of Copolymer Chains at Liquid-Liquid Interfaces: Effect of Sequence Distribution. Macromolecules 1992, 25 (4), 1357-1360. https://doi.org/10.1021/ma00030a023.

(76) Dudowicz, J.; Freed, K. F. Lattice Cluster Theory for Pedestrian. 2. Random Copolymer Systems. Macromolecules 2000, 33 (9), 3467-3477. https://doi.org/10.1021/ma991747g.

(77) Gersappe, D.; Balazs, A. C. Random Copolymers as Effective Compatibilizing Agents. Phys. Rev. E 1995, 52 (5), 50615064. https://doi.org/10.1103/PhysRevE.52.5061.

(78) Houdayer, J.; Müller, M. Phase Diagram of Random Copolymer Melts: A Computer Simulation Study. Macromolecules 2004, 37 (11), 4283-4295. https://doi.org/10.1021/ma035814p.

(79) Matsumoto, M.; Sawamoto, M.; Terashima, T. Orthogonal Folding of Amphiphilic/Fluorous Random Block Copolymers for Double and Multicompartment Micelles in Water. ACS Macro Lett. $\quad 2019, \quad 8 \quad$ (3), 320-325. https://doi.org/10.1021/acsmacrolett.9b00078.

(80) Imai, S.; Hirai, Y.; Nagao, C.; Sawamoto, M.; Terashima, T. Programmed Self-Assembly Systems of Amphiphilic Random Copolymers into Size-Controlled and Thermoresponsive Micelles in Water. Macromolecules 2018, $51 \quad$ (2), 398-409. https://doi.org/10.1021/acs.macromol.7b01918.

(81) Terashima, T.; Sugita, T.; Fukae, K.; Sawamoto, M. Synthesis and Single-Chain Folding of Amphiphilic Random Copolymers in Water. Macromolecules 2014, 47 (2), 589-600. https://doi.org/10.1021/ma402355v.

(82) Patterson, A. L.; Danielsen, S. P. O.; Yu, B.; Davidson, E. C.; Fredrickson, G. H.; Segalman, R. A. Sequence Effects on Block Copolymer Self-Assembly through Tuning Chain Conformation and Segregation Strength Utilizing Sequence-Defined Polypeptoids. Macromolecules 2019, 52 (3), 1277-1286. https://doi.org/10.1021/acs.macromol.8b02298.

(83) Merrifield, R. B. Solid Phase Pepetide Synthesis. I. The Synthesis of a Tetrapeptide. J Am Chem Soc 1963, 85, 2149-2154.
(84) Lytle, T. K.; Chang, L.-W.; Markiewicz, N.; Perry, S. L.; Sing, C. E. Designing Electrostatic Interactions via Polyelectrolyte Monomer Sequence. ACS Cent Sci 2019, 5 (4), 709-718. https://doi.org/10.1021/acscentsci.9b00087.

(85) Chang, L. W.; Lytle, T. K.; Radhakrishna, M.; Madinya, J. J.; Vélez, J.; Sing, C. E.; Perry, S. L. Sequence and EntropyBased Control of Complex Coacervates. Nat Commun 2017, 8 (1), 1273. https://doi.org/10.1038/s41467-017-01249-1.

(86) Gucht, J. van der; Spruijt, E.; Lemmers, M.; Stuart, M. A. C. Polyelectrolyte Complexes: Bulk Phases and Colloidal Systems. J Colloid Interface Sci 2011, 361, 407-422.

(87) Srivastava, S.; Tirrell, M. V. Advances in Chemical Physics; Rice, S. A., Dinner, A. R., Eds.; John Wiley and Sons: Hoboken, NJ, 2016.

(88) Madinya, J. J.; Chang, L.-W.; Perry, S. L.; Sing, C. E. Sequence-Dependent Self-Coacervation in High Charge-Density Polyampholytes. Mol Syst Eng 2019, DOI:10.1039/C9ME00074G.

(89) Seeberger, P. H. Automated Oligosaccharide Synthesis. Chem Soc Rev 2008, 37 (1), 19-28. https://doi.org/10.1039/B511197H.

(90) Caruthers, M. H. Gene Synthesis Machines: DNA Chemistry and Its Uses. Science 1985, 230, 281-285.

(91) Amblard, M.; Fehrentz, J. A.; Martinez, J.; Subra. Methods and Protocols of Modern Solid Phase Peptide Synthesis. Mol Biotechnol 2006, 33, 239-254. https://doi.org/10.1385/MB:33:3:239.

(92) Culf, A. S.; Ouellette, R. J. Solid-Phase Synthesis of NSubstituted Glycine Oligomers (A-Peptoids) and Derivatives. Mole$\begin{array}{llll}\text { cules } & \mathbf{2 0 1 0}, & 15 & \text { (8), }\end{array}$ https://doi.org/10.3390/molecules 15085282.

(93) Leibfarth, F. A.; Johnson, J. A.; Jamison, T. F. Scalable Synthesis of Sequence-Defined, Unimolecular Macromolecules by Flow-IEG. Proc. Natl. Acad. Sci. 2015, 112 (34), 10617-10622. https://doi.org/10.1073/pnas.1508599112.

(94) Ngo, J. T.; Tirrell, D. A. Noncanonical Amino Acids in the Interrogation of Cellular Protein Synthesis. Acc. Chem. Res. 2011, 44 (9), 677-685. https://doi.org/10.1021/ar200144y.

(95) Tang, N. C.; Chilkoti, A. Combinatorial Codon Scrambling Enables Scalable Gene Synthesis and Amplification of Repetitive Proteins. Nat. Mater. 2016, 15 (4), 419-424. https://doi.org/10.1038/nmat4521.

(96) Wu, D.; Sinha, N.; Lee, J.; Sutherland, B. P.; Halaszynski, N. I.; Tian, Y.; Caplan, J.; Zhang, H. V.; Saven, J. G.; Kloxin, C. J.; Pochan, D.J. Polymers with Controlled Assembly and Rigidity Made with Click-Functional Peptide Bundles. Nature 2019, 574 (7780), 658-662. https://doi.org/10.1038/s41586-019-1683-4.

(97) Mao, S.; MacPherson, Q.; Qin, J.; Spakowitz, A. J. FieldTheoretic Simulations of Random Copolymers with Structural Rigidity. Soft Matter 2017, DOI: 10.1039/C7SM00164A.

(98) Mao, S.; MacPherson, Q. J.; He, S. S.; Coletta, E.; Spakowitz, A. J. Impact of Conformational and Chemical Correlations on Microphase Segregation in Random Copolymers. Macromolecules 2016, 49, 4358-4368.

(99) Sing, C. E. Micro- to Macro-Phase Separation Transition in Sequence-Defined Coacervates. J Chem Phys 2020, In Press.

(100) Lytle, T. K.; Salazar, A. J.; Sing, C. E. Interfacial Properties of Polymeric Complex Coacervates from Simulation and Theory. J Chem Phys 2018, 149 (16), 163315.

(101) Ong, G. M. C.; Sing, C. E. Mapping the Phase Behavior of Coacervate-Driven Self-Assembly in Diblock Copolyelectrolytes. $\begin{array}{llll}\text { Soft } & \text { Matter } & \text { 2019, } & \text { 5116-5127. }\end{array}$ https://doi.org/10.1039/C9SM00741E.

(102) Lytle, T. K.; Radhakrishna, M.; Sing, C. E. High Charge Density Coacervate Assembly via Hybrid Monte Carlo Single Chain in Mean Field Theory. Macromolecules 2016, 49 (24), 9693-9705. https://doi.org/10.1021/acs.macromol.6b02159.

(103) Lytle, T. K.; Sing, C. E. Transfer Matrix Theory of Polymer Complex Coacervation. Soft Matter 2017, 13 (39), 70017012. https://doi.org/10.1039/c7sm01080j.

(104) Rosales, A. M.; Murnen, H. K.; Zuckermann, R. N.; Segalman, R. A. Control of Crystallization and Melting Behavior in 
Sequence Specific Polypeptoids. Macromolecules 2010, 43 (13), 5627-5636. https://doi.org/10.1021/ma1002563.

(105) Petit, B. É.; Lotz, B.; Lutz, J.-F. About the Crystallization of Abiotic Coded Matter. ACS Macro Lett. 2019, 8 (7), 779-782. https://doi.org/10.1021/acsmacrolett.9b00307.

(106) Qiang, Z.; Shebek, K. M.; Irie, M.; Wang, M. A Polymerizable Photoswitchable Fluorophore for Super-Resolution Imaging of Polymer Self-Assembly and Dynamics. ACS Macro Lett. 2018, 7 (12), 1432-1437. https://doi.org/10.1021/acsmacrolett.8b00686.

(107) Qiang, Z.; Li, L.; Torkelson, J. M.; Wang, M. Determining Order-to-Disorder Transitions in Block Copolymer Thin Films Using a Self-Referencing Fluorescent Probe. Mol. Syst. Des. Eng. 2020,

10.1039.C9ME00091G. https://doi.org/10.1039/C9ME00091G.

(108) Wang, M.; Marr, J. M.; Davanco, M.; Gilman, J. W.; Liddle, J. A. Nanoscale Deformation in Polymers Revealed by Single-Molecule Super-Resolution Localization-Orientation Microscopy. Mater. Horiz. 2019, 6 (4), 817-825. https://doi.org/10.1039/C8MH01187G.

(109) Gramlich, M. W.; Bae, J.; Hayward, R. C.; Ross, J. L. Fluorescence Imaging of Nanoscale Domains in Polymer Blends Using Stochastic Optical Reconstruction Microscopy (STORM). $\begin{array}{llllll}\text { Opt. } & \text { Express } & \text { 2014, } & 22 & \text { (7), } & 8438 .\end{array}$ https://doi.org/10.1364/OE.22.008438.

(110) Christie, D.; Register, R. A.; Priestley, R. D. Direct Measurement of the Local Glass Transition in Self-Assembled Copolymers with Nanometer Resolution. ACS Cent. Sci. 2018, 4 (4), 504-511. https://doi.org/10.1021/acscentsci.8b00043.

(111) Kong, H. J.; Kim, C. J.; Huebsch, N.; Weitz, D.; Mooney, D. J. Noninvasive Probing of the Spatial Organization of Polymer Chains in Hydrogels Using Fluorescence Resonance Energy Transfer (FRET). J. Am. Chem. Soc. 2007, 129 (15), 4518-4519. https://doi.org/10.1021/ja0690058.

(112) Brini, E.; Algaer, E. A.; Ganguly, P.; Li, C.; RodríguezRopero, F.; van der Vegt, N. F. A. Systematic Coarse-Graining Methods for Soft Matter Simulations - a Review. Soft Matter 2013, 9 (7), 2108-2119. https://doi.org/10.1039/C2SM27201F.

(113) Lin, Y. H.; Chan, H. S. Phase Separation and SingleChain Compactness of Charged Disordered Proteins Are Strongly Correlated. Biophys J 2017, 112 (10), 2043-2046. https://doi.org/10.1016/j.bpj.2017.04.021.

(114) Lin, Y.-H.; Forman-Kay, J. D.; Chan, H. S. SequeneSpecific Polyampholyte Phase Separation in Membraneless Organelles. Phys Rev Lett 2016, 117, 178101.

(115) Rumyantsev, A. M.; Jackson, N. E.; Yu, B.; Ting, J. M.; Chen, W.; Tirrell, M. V.; de Pablo, J. J. Controlling Complex Coacervation via Random Polyelectrolyte Sequences. ACS Macro Lett. 2019, 8 (10), 1296-1302. https://doi.org/10.1021/acsmacrolett.9b00494.

(116) Lin, Y. H.; Song, J.; Forman-Kay, J. D.; Chan, H. S. Random-Phase-Approximation Theory for Sequence-Dependent, Biologically Functional Liquid-Liquid Phase Separation of Intrinsically Disordered Proteins. J Mol Liq 2017, 228, 176-193. https://doi.org/10.1016/j.molliq.2016.09.090.

(117) Fredrickson, G. The Equilibrium Theory of Inhomogeneous Polymers; Oxford University Press, 2013.

(118) Danielsen, S. P. O.; McCarty, J.; Shea, J.-E.; Delaney, K. T.; Fredrickson, G. H. Molecular Design of Self-Coacervation Phenomena in Block Polyampholytes. Proc Natl Acad Sci U A 2019, 8224-8232. https://doi.org/10.1073/pnas.1900435116.

(119) Danielsen, S. P. O.; McCarty, J.; Shea, J.-E.; Delaney, K T.; Fredrickson, G. H. Small Ion Effects on Self-Coacervation Phenomena in Block Polyampholytes. J Chem Phys 2019, 151, 034904.

(120) McCarty, J.; Delaney, K. T.; Danielsen, S. P. O.; Fredrickson, G. H.; Shea, J.-E. Complete Phase Diagram for Liquid-Liquid Phase Separation of Intrinsically Disordered Proteins. $J$ Phys Chem Lett 2019, 10 (8), 1644-1652. https://doi.org/10.1021/acs.jpclett.9b00099.

(121) Detcheverry, F. A.; Pike, D. Q.; Nealey, P. F.; Müller, M.; de Pablo, J. J. Monte Carlo Simulation of Coarse Grain Poly- meric Systems. Phys. Rev. Lett. 2009, 102 (19), 197801. https://doi.org/10.1103/PhysRevLett.102.197801.

(122) Muller, M.; Smith, G. D. Phase Separation in Binary Mixtures Containing Polymers: A Quantitative Comparison of Single-Chain-in-Mean-Field Simulations and Computer Simulations of the Corresponding Multichain Systems. J Poly Sci Part B Poly Phys 2005, 43, 934-958.

(123) Daoulas, K. Ch.; Muller, M.; de Pablo, J. J.; Nealey, P. F.; Smith, G. D. Morphology of Multi-Component Polymer Systems: Single Chain in Mean Field Simulation Studies. Soft Matter 2006, 2, 573-583.

(124) Mao, S.; MacPherson, Q.; Spakowitz, A. J. Polymer Semiflexibility Induces Nonuniversal Phase Transitions in Diblock Copolymers. Phys. Rev. Lett. 2018, 120 (6), 067802. https://doi.org/10.1103/PhysRevLett.120.067802.

(125) Meenakshisundaram, V.; Hung, J.-H.; Patra, T. K.; Simmons, D. S. Designing Sequence-Specific Copolymer Compatibilizers Using a Molecular-Dynamics-Simulation-Based Genetic Algorithm. Macromolecules 2017, 50, 1155-1166.

(126) Elder, R. M.; Jayaraman, A. J. Molecular Simulations of Polycation-DNA Binding Exploring the Effect of Peptide Chemistry and Sequence in Nuclear Localization Sequence Based Polycations. J Phys Chem B 2013, 117, 11988-11999.

(127) Jeon, J.; Dobrynin, A. V. Monte Carlo Simulations of Polyampholyte-Polyelectrolyte Complexes: Effect of Charge Sequence and Strength of Electrostatic Interactions. Phys. Rev. E 2003, 67 (6), 061803. https://doi.org/10.1103/PhysRevE.67.061803.

(128) Baughman, T. W.; Chan, C. D.; Winey, K. I.; Wagener, K. B. Synthesis and Morphology of Well-Defined Poly(EthyleneCo -Acrylic Acid) Copolymers. Macromolecules 2007, 40 (18), 6564-6571. https://doi.org/10.1021/ma070841r.

(129) Aitken, B. S.; Buitrago, C. F.; Heffley, J. D.; Lee, M.; Gibson, H. W.; Winey, K. I.; Wagener, K. B. Precision Ionomers: Synthesis and Thermal/Mechanical Characterization. Macromolecules 2012, 45 (2), 681-687. https://doi.org/10.1021/ma202304s.

(130) Seitz, M. E.; Chan, C. D.; Opper, K. L.; Baughman, T. W.; Wagener, K. B.; Winey, K. I. Nanoscale Morphology in Precisely Sequenced Poly(Ethylene-Co-Acrylic Acid) Zinc Ionomers. $J$ Am Chem Soc 2010, 132, 8165-8174.

(131) Hall, L. M.; Seitz, M. E.; Winey, K. I.; Opper, K. L.; Wagener, K. B.; Stevens, M. J.; Friscknecht, A. L. Ionic Aggregate Structure in Ionomer Melts: Effect of Molecular Architecture on Aggregates and the Ionomer Peak. J Am Chem Soc 2012, 134, 574 587.

(132) Hall, L. M.; Stevens, M. J.; Frischknecht, A. L. Dynamics of Model Ionomer Melts of Various Architectures. Macromole$\begin{array}{lllll}\text { cules } & \mathbf{2 0 1 2}, & 45 & \text { (19), } & \text { 8097-8108. }\end{array}$ https://doi.org/10.1021/ma301308n.

(133) Hall, L. M.; Stevens, M. J.; Frischknecht, A. L. Effect of Polymer Architecture and Ionic Aggregation on the Scattering Peak in Model Ionomers. Phys. Rev. Lett. 2011, 106 (12), 127801. https://doi.org/10.1103/PhysRevLett.106.127801.

(134) Prhashanna, A.; Taylor, P. A.; Qin, J.; Kiick, K. L.; Jayaraman, A. Effect of Peptide Sequence on the LCST-Like Transition of Elastin-Like Peptides and Elastin-Like Peptide-Collagen-Like Peptide Conjugates: Simulations and Experiments. Biomacromole$\begin{array}{lllll}\text { cules } & \mathbf{2 0 1 9}, & 20 & \text { (3), }\end{array}$ https://doi.org/10.1021/acs.biomac.8b01503.

(135) Davidson, E. C.; Rosales, A. M.; Patterson, A. L.; Russ, B.; Yu, B.; Zuckermann, R. N.; Segalman, R. A. Impact of Helical Chain Shape in Sequence-Defined Polymers on Polypeptoid Block Copolymer Self-Assembly. Macromolecules 2018, 51 (5), 20892098. https://doi.org/10.1021/acs.macromol.8b00055.

(136) Panganiban, B.; Qiao, B.; Jiang, T.; DelRe, C.; Obadia, M. M.; Nguyen, T. D.; Smith, A. A. A.; Hall, A.; Sit, I.; Crosby, M. G.; Dennis, P.B.; Drockenmuller, E.; Olvera de la Cruz, M.; Xu, T. Random Heteropolymers Preserve Protein Function in Foreign Environments. Science 2018, 359, 1239-1243.

(137) Brown, J. S.; Acevedo, Y. M.; He, G. D.; Freed, J. H.; Clancy, P.; Alabi, C. A. Synthesis and Solution-Phase Characteriza- 
tion of Sulfonated Oligothioetheramides. Macromolecules 2017, 50 (21), 8731-8738. https://doi.org/10.1021/acs.macromol.7b01915.

(138) Luo, M.; Brown, J. R.; Remy, R. A.; Scott, D. M.; Mackay, M. E.; Hall, L. M.; Epps, T. H. Determination of Interfacial Mixing in Tapered Block Polymer Thin Films: Experimental and Theoretical Investigations. Macromolecules 2016, 49 (14), 52135222. https://doi.org/10.1021/acs.macromol.6b00946.

(139) Ferguson, A. L. Machine Learning and Data Science in Soft Materials Engineering. J. Phys. Condens. Matter 2018, 30 (4), 043002. https://doi.org/10.1088/1361-648X/aa98bd.

(140) Jackson, N. E.; Webb, M. A.; de Pablo, J. J. Recent Advances in Machine Learning towards Multiscale Soft Materials Design. Curr. Opin. Chem. Eng. 2019, 23, 106-114. https://doi.org/10.1016/j.coche.2019.03.005.

(141) Khokhlov, A. R.; Khalatur, P. G. Protein-like Copolymers: Computer Simulation. Phys. A 1998, 9.

(142) Khokhlov, A. R.; Khalatur, P. G. ConformationDependent Sequence Design (Engineering) of AB Copolymers. Phys. Rev. Lett. 1999, 82 (17), 3456-3459. https://doi.org/10.1103/PhysRevLett.82.3456.

(143) Sun, S.; Brem, R.; Chan, H. S.; Dill, K. A. Designing Amino Acid Sequences to Fold with Good Hydrophobic Cores. Protein Eng. Des. Sel. 1995, 8 (12), 1205-1213. https://doi.org/10.1093/protein/8.12.1205.

(144) Bratko, D.; Chakraborty, A. K.; Shakhnovich, E. I. Recognition between Random Heteropolymers and Multifunctional Disordered Surfaces. Chem. Phys. Lett. 1997, 280 (1-2), 46-52. https://doi.org/10.1016/S0009-2614(97)01075-0.
(145) Golumbfskie, A. J.; Pande, V. S.; Chakraborty, A. K. Simulation of Biomimetic Recognition between Polymers and Surfaces. Proc. Natl. Acad. Sci. 1999, 96 (21), 11707-11712. https://doi.org/10.1073/pnas.96.21.11707.

(146) Jayaraman, A.; Hall, C. K.; Genzer, J. Designing PatternRecognition Surfaces for Selective Adsorption of Copolymer Sequences Using Lattice Monte Carlo Simulation. Phys. Rev. Lett. 2005, $\quad 94 \quad$ (7), 078103. https://doi.org/10.1103/PhysRevLett.94.078103.

(147) Jhon, Y. K.; Semler, J. J.; Genzer, J.; Beevers, M.; Gus'kova, O. A.; Khalatur, P. G.; Khokhlov, A. R. Effect of Comonomer Sequence Distribution on the Adsorption of Random Copolymers onto Impenetrable Flat Surfaces. Macromolecules 2009, 42 (7), 2843-2853. https://doi.org/10.1021/ma8027936.

(148) Lau, K. F.; Dill, K. A. A Lattice Statistical Mechanics Model of the Conformational and Sequence Spaces of Proteins. Macromolecules $\quad 1989, \quad 22 \quad$ (10), 3986-3997. https://doi.org/10.1021/ma00200a030.

(149) Murnen, H. K.; Khokhlov, A. R.; Khalatur, P. G.; Segalman, R. A.; Zuckermann, R. N. Impact of Hydrophobic Sequence Patterning on the Coil-to-Globule Transition of Protein-like Polymers. Macromolecules 2012, 45, 5229-5236.

(150) Gody, G.; Zetterlund, P. B.; Perrier, S.; Harrisson, S. The Limits of Precision Monomer Placement in Chain Growth Polymerization. Nat. Commun. 2016, 7 (1), 10514. https://doi.org/10.1038/ncomms10514. 


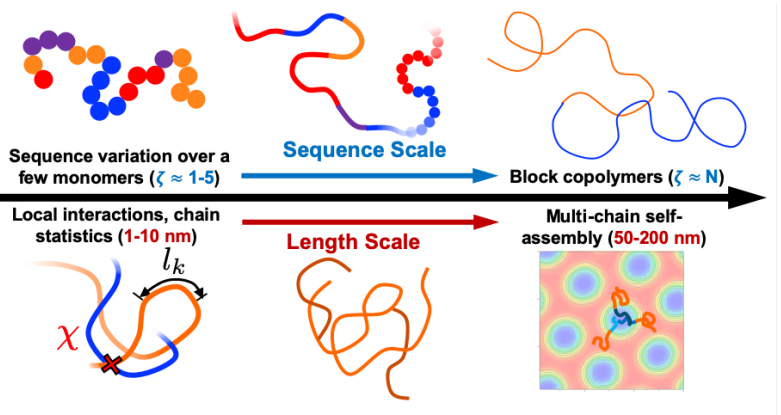

